\title{
Missed diagnosis and delayed treatment of acromegaly in a patient with severe diabetes: A case report
}

\author{
KOTA NISHIHAMA $^{1}$, YUTAKA YANO ${ }^{1}$, TARO YASUMA ${ }^{1,2}$ and ESTEBAN C. GABAZZA ${ }^{2}$ \\ Departments of ${ }^{1}$ Diabetes, Metabolism and Endocrinology, and ${ }^{2}$ Immunology, \\ Mie University Graduate School of Medicine, Tsu, Mie 514-8507, Japan
}

Received February 11, 2020; Accepted September 11, 2020

DOI: $10.3892 /$ etm.2020.9394

\begin{abstract}
The early stages of acromegaly are characterized by slow and progressive acral overgrowth without major systemic complications. Failure to diagnose acromegaly at an early stage may have devastating consequences on patient care. The case in the present report was a 44-year-old Japanese man, referred to Kuwana City Medical Center due to severe hyperglycemia detected in a general checkup. The patient had no acromegaly-related complaints. Laboratory data revealed high blood levels of hemoglobin A1c and glucose. Careful physical examination revealed enlargement of extremities and soft tissues. Laboratory investigation indicated a high blood concentration of growth hormone, and magnetic resonance imaging disclosed an enhanced pituitary tumor. The diagnosis was pituitary tumor-associated acromegaly with severe diabetic complications. The pituitary tumor became large and unresectable following 10 years of misdiagnosis. The patient was treated with somatostatin receptor ligands (lanreotide and pasireotide), as well as bromocriptine in Mie University Hospital. The tumor size was reduced following treatment, though it was still unresectable at the time of this report. The case highlights the importance of hyperglycemia and abnormal manifestations of the feet in patients with acromegaly. In addition, these findings highlight the need for a thorough examination of the feet in diabetic patients, and the critical importance of the early diagnosis of acromegaly for preventing the consequences of inappropriate patient care.
\end{abstract}

\section{Introduction}

The most frequent cause of acromegaly is pituitary hypersecretion of growth hormone $(\mathrm{GH})(1)$. High levels of $\mathrm{GH}$ and insulin-like growth factor-1 (IGF-1) result in systemic

Correspondence to: Professor Esteban C. Gabazza, Department of Immunology, Mie University Graduate School of Medicine, Edobashi 2-174, Tsu, Mie 514-8507, Japan

E-mail: gabazza@doc.medic.mie-u.ac.jp

Key words: acromegaly, diabetes, pituitary adenoma, growth hormone, surgical therapy alterations such as acral enlargement, skin thickening, soft tissue hyperplasia and excessive sweating (1). Acromegaly may also be associated with dyslipidemia, insulin resistance, diabetes mellitus and cardiovascular events (1-3). Previous reports have revealed increased overall mortality rates in patients with acromegaly compared with the healthy control population (4). Acromegaly-associated physical alterations may not be detected by the patients at the early stages of disease $(5,6)$. However, health professionals may also misdiagnose acromegaly in patients exhibiting slow disease progression and limited symptoms (1). As previously reported, diagnostic error may notably impact therapeutic management, prognosis and patient quality of life (7). Diagnostic error has also been the cause of numerous lawsuits of medical malpractice (8). The present report outlines a case of acromegaly that was undiagnosed for multiple years, which affected the therapeutic management of the patient.

\section{Case report}

The case was a 44-year-old Japanese man referred to the Department of Internal Medicine, Kuwana City Medical Center (Kuwana, Mie, Japan) in October 2017 for severe hyperglycemia, which was detected during a general workplace checkup. The patient experienced mild hyperglycemia during a medical check-up five years before admission, without subsequent medical follow-up. The clinical findings during the examination were as follows: Height, $168 \mathrm{~cm}$; body weight, $77 \mathrm{~kg}$; body mass index, $27.3 \mathrm{~kg} / \mathrm{m}^{2}$; blood pressure, 110/64 $\mathrm{mmHg}$; heart rate, 70 beats/min; and body temperature, $36.9^{\circ} \mathrm{C}$. The laboratory data revealed a hemoglobin A1c level of $15.8 \%$ and a random blood glucose level of $330 \mathrm{mg} / \mathrm{dl}$ (Table I). A routine physical foot examination for diabetic patients revealed enlargement of both feet (Fig. 1A). The feet had no pitting-edema and were not painful, red or warm. Additional physical examination disclosed hyperhidrosis, jaw malocclusion, prominent supraciliary arches and enlarged hands and tongue (Fig. 1A-C). The patient was transferred to the Department of Diabetes and Endocrinology of Mie University Hospital (Tsu, Mie, Japan) as he was suspected of having an endocrine disorder. A plain radiograph indicated hypertrophied terminal phalangeal tufts and soft tissue hypertrophy (Fig. 2A) with heel pad thickness (Fig. 2B). 
Table I. Endocrine parameters.

\begin{tabular}{|c|c|c|}
\hline Variable & Value & $\begin{array}{c}\text { Reference } \\
\text { range }\end{array}$ \\
\hline $\mathrm{GH}, \mathrm{ng} / \mathrm{ml}$ & 870 & $<1.0$ \\
\hline $\mathrm{IGF}-1, \mathrm{ng} / \mathrm{ml}$ & 582 & $92-255$ \\
\hline Random blood glucose, $\mathrm{mg} / \mathrm{dl}$ & 330 & $<200$ \\
\hline HbA1c $(\%)$ & 15.8 & $4.9-6.0$ \\
\hline $\mathrm{TSH}^{\mathrm{a}}(\mu \mathrm{IU} / \mathrm{ml})$ & 0.84 & $0.35-4.9$ \\
\hline Free $\mathrm{T}^{\mathrm{a}}(\mathrm{pg} / \mathrm{ml})$ & 1.80 & $1.7-3.7$ \\
\hline Free $\mathrm{T}^{\mathrm{a}}{ }^{\mathrm{a}}(\mathrm{ng} / \mathrm{dl})$ & 0.79 & $0.70-1.48$ \\
\hline $\mathrm{LH}^{\mathrm{a}}(\mathrm{mIU} / \mathrm{ml})$ & 0.44 & $0.57-12.07$ \\
\hline $\mathrm{FSH}^{\mathrm{a}}(\mathrm{mIU} / \mathrm{ml})$ & 2.11 & $0.95-11.95$ \\
\hline $\mathrm{ACTH}^{\mathrm{a}}(\mathrm{pg} / \mathrm{ml})$ & 43.4 & $7.2-63.3$ \\
\hline $\operatorname{Cortisol}^{\mathrm{a}}(\mu \mathrm{g} / \mathrm{dl})$ & 8.3 & $4.5-21.1$ \\
\hline $\mathrm{PRL}^{\mathrm{a}}$ (ng/ml) & 5.9 & $3.6-12.8$ \\
\hline $\operatorname{AVP}^{\mathrm{a}}(\mathrm{pg} / \mathrm{ml})$ & 1.7 & $<2.8$ \\
\hline Serum osmolality $^{\mathrm{a}}\left(\mathrm{mOsm} / \mathrm{kg} / \mathrm{H}_{2} \mathrm{O}\right)$ & 295 & $275-295$ \\
\hline
\end{tabular}

aParameters measured on the second visit. GH, growth hormone; IGF-1; insulin-like growth; HbA 1c, hemoglobin A1c; TSH, thyroid stimulating hormone; T3, triiodothyronine; T4, thyroxine; LH, luteinizing hormone; FSH, follicle stimulating hormone; ACTH, adrenocorticotropic hormone; PRL, prolactin; AVP, arginine vasopressin.

Table I describes the results of endocrine parameter analysis. There was an increased serum concentration of GH and IGF-I, and the serum level of luteinizing hormone was low. However, the circulating levels of adrenocorticotropic hormone, thyroid stimulation hormone, follicle-stimulating hormone, free triiodothyronine, free thyroxine and cortisol were within the normal range. The circulating levels of prolactin and arginine vasopressin, as well as the serum osmolality, were also within the normal range. As presented in Table II, a luteinizing-hormone releasing hormone test revealed that the levels of luteinizing hormone and follicle-stimulating hormone were also normal (6). Magnetic resonance imaging (MRI) revealed an enhanced pituitary tumor of $4.5 \mathrm{~cm}$ (Fig. 2C and D). Ophthalmic examinations revealed no vision loss secondary to the pituitary tumor or diabetic retinopathy (Fig. 2E). There were no symptoms of Cushing's syndrome, and the overall results of the corticotropin-releasing hormone stimulation test showed no significant abnormality (Table II) (9). A test for cortisol rhythm was not performed.

The patient was diagnosed with acromegaly, type 2 diabetes mellitus and acromegaly-associated exacerbation of diabetes mellitus. However, tumor removal will ultimately clarify whether type 2 diabetes mellitus is only secondary to acromegaly. Subsequent investigation disclosed the presence of sleep apnea, colon polyps and thyroid enlargement; based on a previous report (10). The summary of positive clinical findings of acromegaly in the present case was as follows: Pituitary gland tumor, acral enlargement, jaw malocclusion, hyperhidrosis, colon polyps, left ventricular hypertrophy, sleep apnea, diabetes mellitus, dyslipidemia and enlargement of tongue and thyroid gland (10). In the
Table II. Results of CRH and LHRH tests.

\begin{tabular}{lccc}
\hline & \multicolumn{3}{c}{ Time of measurement } \\
\cline { 2 - 4 } Variable & $0 \mathrm{~min}$ & $30 \mathrm{~min}$ & $60 \mathrm{~min}$ \\
\hline CRH test & & & \\
ACTH, $\mathrm{pg} / \mathrm{ml}$ & 55.3 & 62.1 & 47.2 \\
Cortisol, $\mu \mathrm{g} / \mathrm{dl}$ & 20.1 & 21.9 & 17.6 \\
LHRH test & & & \\
LH, $\mathrm{mIU} / \mathrm{ml}$ & 0.56 & 4.91 & 7.29 \\
FSH, $\mathrm{mIU} / \mathrm{ml}$ & 2.65 & 4.37 & 5.48 \\
\hline
\end{tabular}

Parameters were measured on admission.CRH, corticotropin-releasing hormone; LHRH, luteinizing hormone releasing hormone; ACTH, adrenocorticotropic hormone; $\mathrm{LH}$, luteinizing hormone; $\mathrm{FSH}$, follicle stimulating hormone.

present case, the electrocardiogram demonstrated a first-degree atrioventricular blockade (PR interval, $212 \mathrm{~ms}$; reported normal range, 120-200 ms) with no ST-segment changes (11). Echocardiography demonstrated a left-ventricular ejection fraction of 55\% (using the modified Simpson method), diffuse mild left ventricular hypertrophy and mild thickening of the mitral valve (12). The right and left ankle-brachial indexes were 1.19 and 1.22 (reported normal range, 0.9-1.3), respectively (13). Carotid ultrasonography revealed no atherosclerotic changes. Based on previous studies (11-13), an expert (Dr K.S). from the Department of Cardiovascular Medicine (Mie University), recommended no further therapy for these mild cardiovascular changes.

The tumor was unresectable due to excessive enlargement and cavernous sinus invasion. Treatment with somatostatin receptor ligands (SRLs; lanreotide and pasireotide) were recommended, as these compounds can potentially reduce tumor size $(14,15)$. As such, SRLs are the first treatment choice for patients with acromegaly (16). Lanreotide has a high affinity for both somatostatin receptor (SSTR) 2 and SSTR5, and a weak affinity for SSTR3 (16). Pasireotide is able to bind multiple SSTRs (SSTR1, 3, 5 and 2) and with a greater affinity than lanreotide (16). Initially, the use of lanreotide (90 or $120 \mathrm{mg}$ ) was indicated every 4 weeks. In addition to diet and exercise therapy, hypoglycemic agents are the first treatment of choice for those with type 2 diabetes mellitus (17). However, the blood glucose level of the current case was $>300 \mathrm{mg} / \mathrm{dl}$ on admission, and the patient was therefore treated with insulin according to previous clinical guidelines (17). During follow-up and five months after starting therapy with lanreotide, laboratory data revealed decreased circulating levels of GH with increasing doses of lanreotide (Fig. 3A), and a MRI study demonstrated a reduction in tumor size (Fig. 3B-E). A previous study reported that serum GH levels of $>10 \mathrm{ng} / \mathrm{ml}$ were not correlated with serum IGF-1 levels (18). This may explain the persistently high levels of IGF-1, despite the decreased levels of GH, observed in the present case (Fig. 3A). During follow-up, no therapeutic response to lanreotide was observed. Therefore, the patient was subsequently treated with pasireotide ( $40 \mathrm{mg}$ every 4 weeks), in additional to $5 \mathrm{mg}$ bromocriptine per day. Bromocriptine is a dopamine agonist 
A

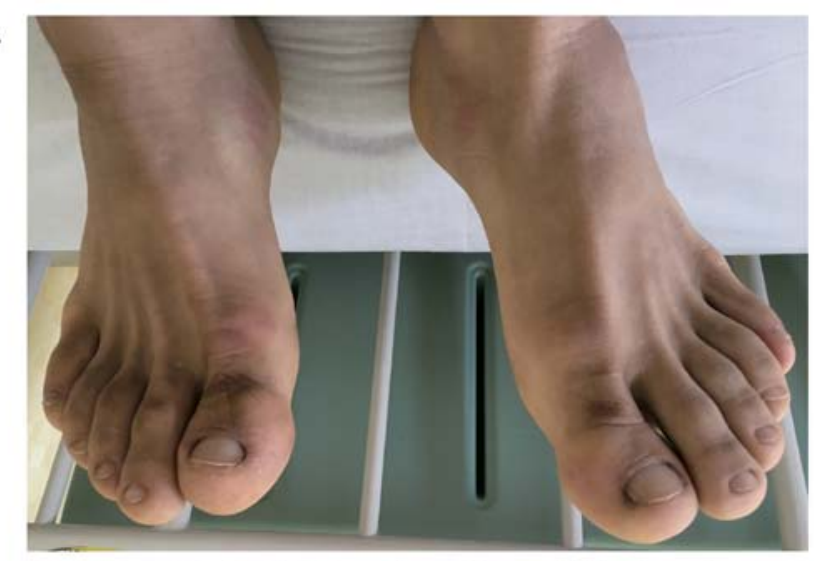

B

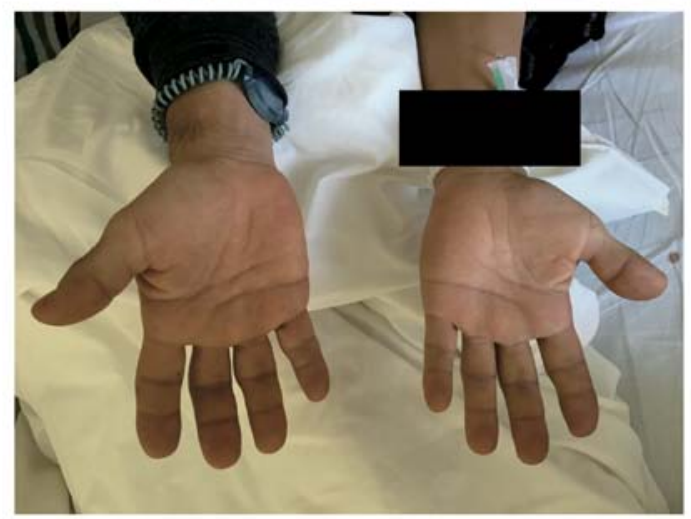

C

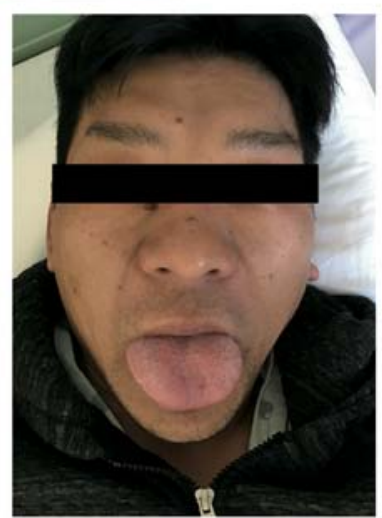

Figure 1. Patient physical examination. (A) Enlarged feet without pitting-edema or symptoms of infection, and enlargement of the (B) hands and (C) tongue.

A

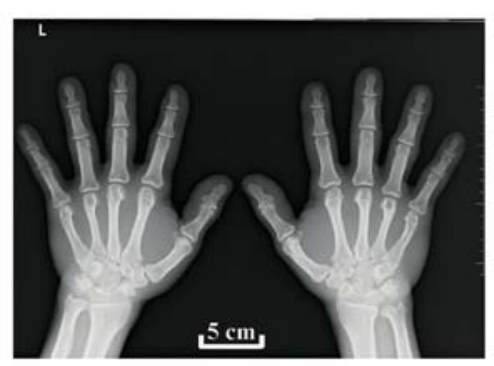

C

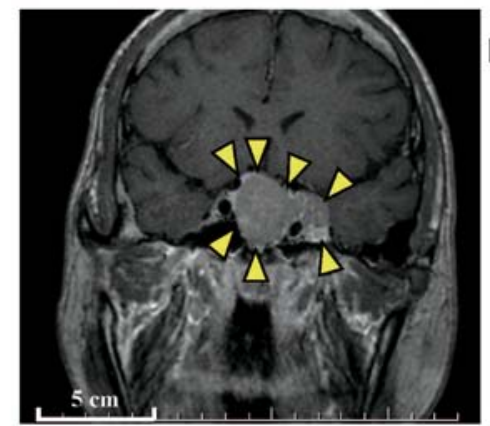

E

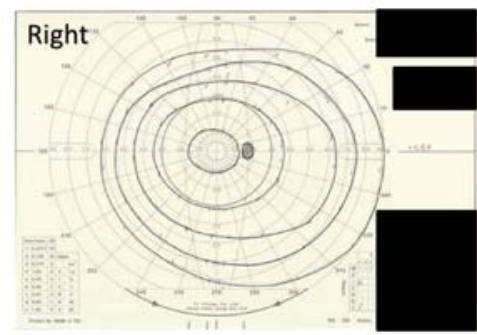

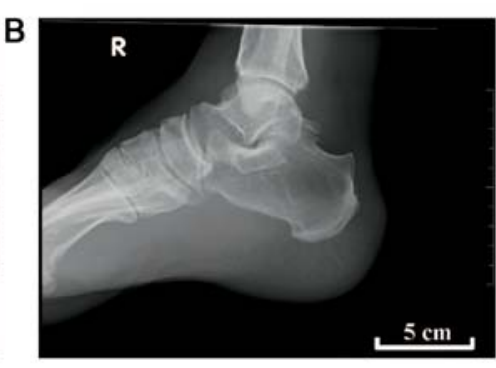

D

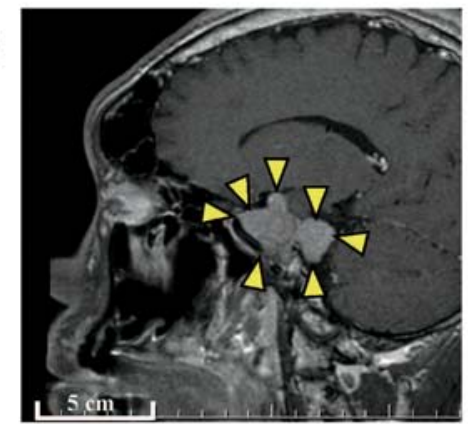

Left

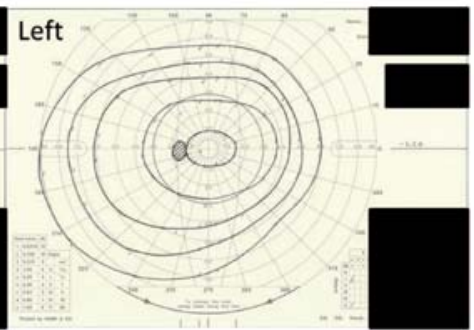

Figure 2. Radiographic and ophthalmic examinations. Radiographic imaging suggested (A) hypertrophied terminal phalangeal tufts and soft tissue hypertrophy, and (B) heel pad thickness. (C and D) Enhanced T1-weighted magnetic resonance imaging revealed a 4.5-cm pituitary tumor involving the left cavernous sinus. (E) Ophthalmic examinations demonstrated no vision loss secondary to the pituitary tumor. 


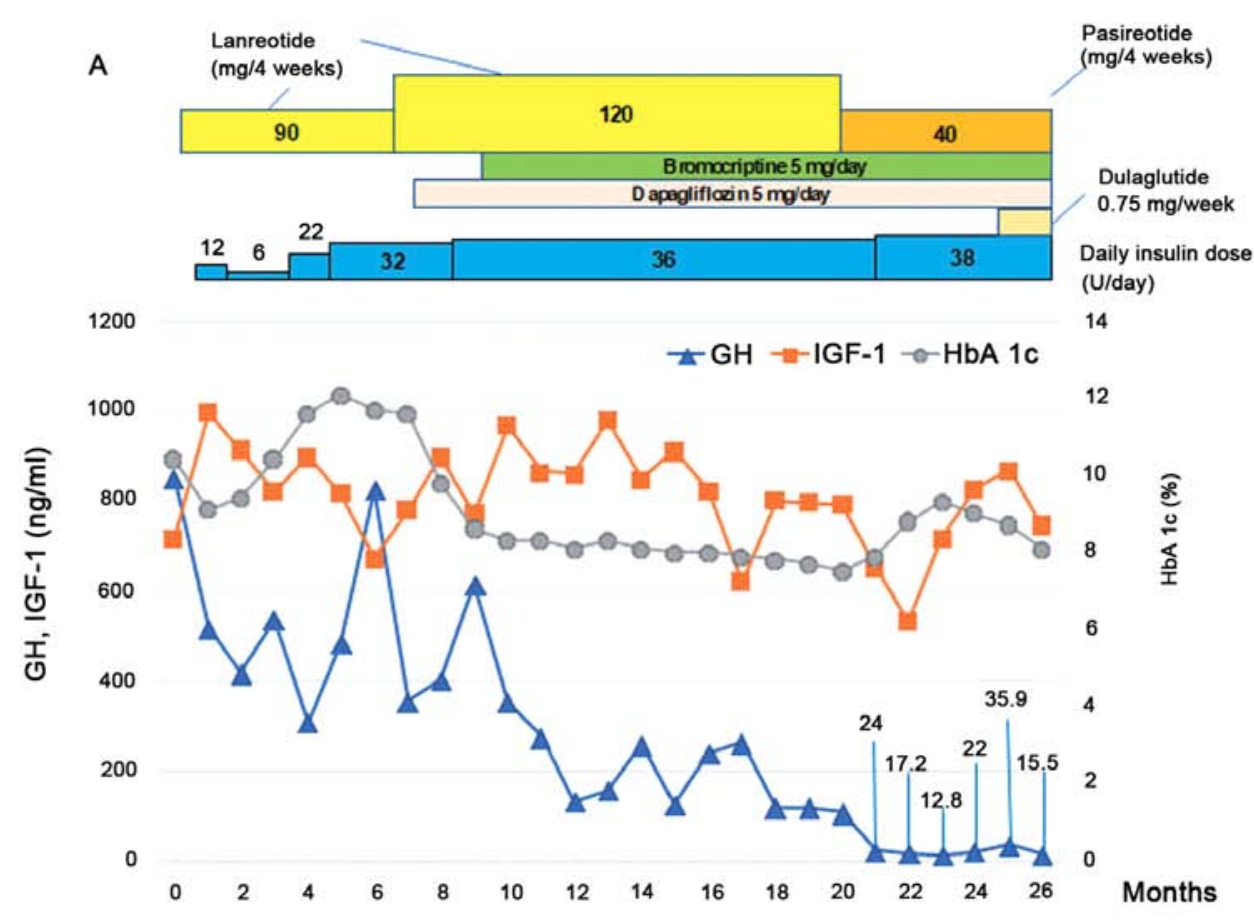

B

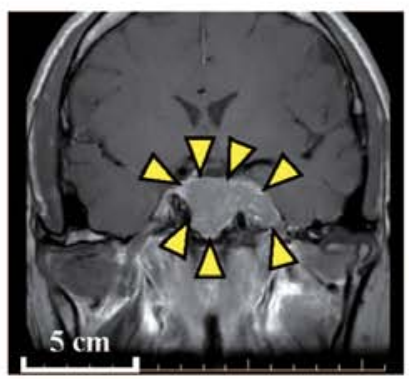

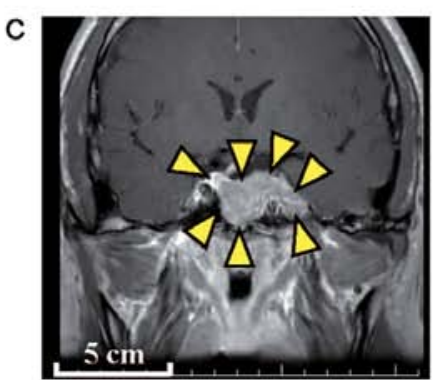

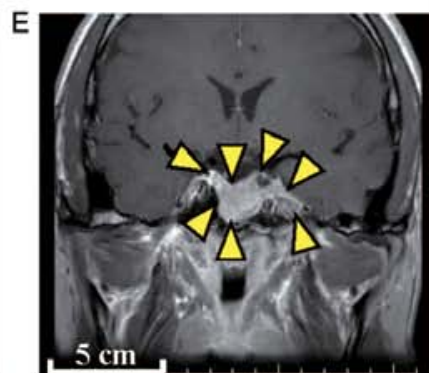

Figure 3. Clinical course of the patient (A) Patient clinical course and treatment, and the results of laboratory analyses. Magnetic resonance imaging demonstrating tumor shrinkage; images were captured (B) 5, (C) 12, (D) 18 and (E) 24 months after treatment. GH, growth hormone; IGF-1; insulin-like growth factor-1; HbA 1c, hemoglobin Alc.

that suppresses GH secretion by binding to the $\mathrm{D} 2$ receptor in the pituitary tumor (16). International consensus statement also recommend the use of cabergoline, a dopamine agonist (14). However, the Japanese Health Insurance System does not cover cabergoline, and therefore, bromocriptine was indicated in the present case (19). A previous report demonstrated the beneficial effects of bromocriptine in acromegaly-associated glucose abnormalities (16). Due to the large size of the tumor and the high levels of circulating of IGF-1, no surgical procedures were indicated at the time of the present report. Tumor debulking surgery will be indicated after appropriate tumor shrinkage.

\section{Discussion}

Acromegaly may reduce the life expectancy of individuals. Metabolic disorders associated with acromegaly accelerate arteriosclerosis and increase the risk of cardiovascular events (20). The first therapeutic option for acromegaly is surgical resection of the pituitary adenoma, although surgery is not feasible in patients with large tumors (6). Patients with unresectable tumors receive treatment with SRLs and GH receptor antagonists (20). However, the lack of an international consensus for the duration of therapy, the high economic burden for the patient and the potential adverse effects associated with the prolonged use of specific SRLs, make the routine indication of these drugs difficult in clinical practice (21). Therefore, the early diagnosis of acromegaly is imperative to successful treatment. However, subtle progressive physical alterations may go unnoticed by patients and attending physicians, leading to delayed or missed diagnoses with detrimental implications for patient care (22). Current clinical guidelines describe the importance of a thorough foot examination for the diagnosis of acromegaly (23); however, available guidelines lack a detailed description of the clinical disease presentations in the presence of comorbidities (such as diabetes mellitus) (23). The present case indicated that, in addition to diabetic foot, acral abnormalities (such as enlarged feet) should also be assessed during the routine examination of patients with untreated diabetes mellitus. The present report is an illustrative case of missed diagnosis of acromegaly that negatively affected medical treatment. Due to a missed diagnosis of acromegaly at the early stages (during routine medical check-ups over numerous years), the patient could not undergo debulking surgery of the pituitary tumor. Therefore, this case also underscores the critical 
importance of early diagnosis for the management of patients with acromegaly.

Another point that could have prevented a missed diagnosis in the present case is the detection of hyperglycemia. Diabetes mellitus is a metabolic disorder that may be associated with acromegaly (20). A cohort study in a Mexican population revealed that, among patients with acromegaly, the incidence of diabetes mellitus appeared to be higher in women than in men (16). However, epidemiological data from other geographical areas revealed no differences between the sexes (4,24-28). Clinical suspicion of acromegaly is generally difficult during anamnesis of patients with diabetes mellitus, particularly in the absence of disease-related symptomatology. However, following routine checkpoints may prevent patients and practitioners from overlooking the signs of acromegaly. The American Diabetes Association recommends a comprehensive and routine foot examination during the initial visits of all diabetic patients $(29,30)$. In addition to evaluating the presence of diabetic foot, peripheral artery disease or diabetic neuropathy, careful foot examination may also provide hints for the early diagnosis of acromegaly. In the present case, laboratory data during the medical check-up disclosed hyperglycemia that was indicative of diabetes mellitus. Failure to examine the foot of the patient, despite the suspicion of diabetes mellitus, was another contributing factor for the missed diagnosis of acromegaly. In the present case, improvement of glucose metabolism after surgical treatment may demonstrate that acromegaly was the cause of hyperglycemia (16). The patient is currently under clinical follow-up, and will undergo surgery when the tumor becomes operable.

Diagnostic error is a frequent cause of patient harm and adverse events in hospital practice and outpatient care $(31,32)$. In 2015, the National Academy of Medicine stated that most individuals 'will experience at least one diagnostic error in their lifetime, sometimes with devastating consequences' (33-35). There are different types of diagnostic errors, such as the wrong diagnosis (misdiagnosis), failure to diagnose (missed diagnosis) and delayed diagnosis (32). Diagnostic errors may be detrimental to patient health, resulting in delayed or inappropriate therapy or diagnostic procedures $(32,33)$. The current report is a typical case of acromegaly where, due to missed diagnosis over a number of years, the most appropriate treatment was not received.

The present report outlines a case of missed diagnosis of acromegaly associated with severe hyperglycemia. After 10 years of missed diagnosis, the associated pituitary tumor became inoperable due to invasive growth into the adjacent tissue. This case highlights the importance of hyperglycemia and abnormal feet in acromegaly. In addition, the case underscores the requirement for a careful examination of the feet of diabetic patients, and the critical importance of early diagnosis of acromegaly to prevent devastating consequences for patient care.

\section{Acknowledgements}

The authors would like to thank Dr Kei Sato from the Department of Cardiology, Mie University Hospital, for his clinical assistance in this case.

\section{Funding}

No funding was received.

\section{Availability of data and materials}

The datasets used and/or analyzed during the current study are available from the corresponding author on reasonable request.

\section{Authors' contributions}

$\mathrm{KN}$ was responsible for clinical treatment, follow-up in Kuwana City Medical Center and Mie University Hospital and preparation of the first draft of the manuscript. YY, TY and ECG contributed to the interpretation of the data and made intellectual contributions for the preparation of the manuscript. All authors read and approved the final manuscript.

\section{Ethics approval and consent to participate}

Not applicable.

\section{Patient consent for publication}

Written informed consent was obtained from the patient for the publication of clinical details and images.

\section{Competing interests}

The authors declare that they have no competing of interests.

\section{References}

1. Colao A, Grasso LFS, Giustina A, Melmed S, Chanson P, Pereira AM and Pivonello R: Acromegaly. Nat Rev Dis Primers 5: 20, 2019.

2. Espinosa-de-los-Monteros AL, González B, Vargas G, Sosa E and Mercado M: Clinical and biochemical characteristics of acromegalic patients with different abnormalities in glucose metabolism. Pituitary 14: 231-235, 2011.

3. González B, Vargas G, de Los Monteros ALE, Mendoza V and Mercado M: Persistence of diabetes and hypertension after multimodal treatment of acromegaly. J Clin Endocrinol Metab 103: 2369-2375, 2018.

4. Dal J, Feldt-Rasmussen U, Andersen M, Kristensen L $\varnothing$ Laurberg P, Pedersen L, Dekkers OM, Sørensen HT and Jørgensen JO: Acromegaly incidence, prevalence, complications and long-term prognosis: A nationwide cohort study. Eur J Endocrinol 175: 181-190, 2016.

5. Caron P, Brue T, Raverot G, Tabarin A, Cailleux A, Delemer B, Renoult PP, Houchard A, Elaraki F and Chanson P: Signs and symptoms of acromegaly at diagnosis: The physician's and the patient's perspectives in the ACRO-POLIS study. Endocrine 63: 120-129, 2019.

6. Melmed S, Kleinberg D and Ho K: Pituitary physiology and diagnostic evaluation. In: Williams Textbook of Endocrinology. Melmed S (ed). Elsevier Saunders, Philadelphia, PA, pp175-228, 2011.

7. Kalra J: Medical errors: An introduction to concepts. Clin Biochem 37: 1043-1051, 2004.

8. Oyebode F: Clinical errors and medical negligence. Med Princ Pract 22: 323-333, 2013

9. Kageyama K, Oki Y, Sakihara S, Nigawara T, Terui K and Suda T: Evaluation of the diagnostic criteria for Cushing's disease in Japan. Endocr J 60: 127-135, 2013.

10. Melmed S: Medical progress: Acromegaly. N Engl J Med 355: 2558-2573, 2006. 
11. Kashou AH, Goyal A, Nguyen T and Chhabra L: Atrioventricular Block. StatPearls, Treasure Island, FL, 2020.

12. Zemaitis MR, Boll JM and Dreyer MA: Peripheral arterial disease. StatPearls, Treasure Island, FL, 2020

13. Colao A, AuriemmaRS, Galdiero M,Lombardi G and Pivonello R: Effects of initial therapy for five years with somatostatin analogs for acromegaly on growth hormone and insulin-like growth factor-I levels, tumor shrinkage, and cardiovascular disease: A prospective study. J Clin Endocrinol Metab 94: 3746-3756, 2009.

14. Melmed S, Bronstein MD, Chanson P, Klibanski A, Casanueva FF Wass JAH, Strasburger CJ, Luger A, Clemmons DR and Giustina A: A consensus statement on acromegaly therapeutic outcomes. Nat Rev Endocrinol 14: 552-561, 2018.

15. Zahr R and Fleseriu M: Updates in diagnosis and treatment of acromegaly. Eur Endocrinol 14: 57-61, 2018.

16. Ferrau F, Albani A, Ciresi A, Giordano C and Cannavo S: Diabetes secondary to acromegaly: Physiopathology, clinical features and effects of treatment. Front Endocrinol (Lausanne) 9 : $358,2018$.

17. Haneda M, Noda M, Origasa H, Noto H, Yabe D, Fujita Y, Goto A, Kondo T and Araki E: Japanese clinical practice guideline for diabetes 2016. Diabetol Int 9: 1-45, 2018.

18. Oldfield EH, Jane JA Jr, Thorner MO, Pledger CL, Sheehan JP and Vance ML: Correlation between GH and IGF-1 during treatment for acromegaly. J Neurosurg 126: 1959-1966, 2017.

19. Matsubayashi K and Kawakami K: Prevalence, incidence, comorbidities, and treatment patterns among Japanese patients with acromegaly: A descriptive study using a nationwide claims database. Endocr J: Jun 10, 2020 (Online ahead of print).

20. Gadelha MR, Kasuki L, Lim DST and Fleseriu M: Systemic complications of acromegaly and the impact of the current treatment landscape: An update. Endocr Rev 40: 268-332, 2019.

21. Kasuki L, Wildemberg LE and Gadelha MR: MANAGEMENT OF ENDOCRINE DISEASE: Personalized medicine in the treatment of acromegaly. Eur J Endocrinol 178: R89-R100, 2018.

22. Graber ML: The incidence of diagnostic error in medicine. BMJ Qual Saf 22 (Suppl 2): ii21-ii27, 2013.

23. Katznelson L, Laws ER Jr, Melmed S, Molitch ME, Murad MH, Utz A and Wass JA; Endocrine Society: Acromegaly: An endocrine society clinical practice guideline. J Clin Endocrinol Metab 99: 3933-3951, 2014.

24. Schöfl C, Franz H, Grussendorf M,Honegger J,Jaursch-Hancke C, Mayr B and Schopohl J; participants of the German Acromegaly Register: Long-term outcome in patients with acromegaly: Analysis of 1344 patients from the German Acromegaly Register. Eur J Endocrinol 168: 39-47, 2013.
25. Mestron A, Webb SM, Astorga R, Benito P, Catala M, Gaztambide S, Gomez JM, Halperin I, Lucas-Morante T, Moreno B, et al: Epidemiology, clinical characteristics, outcome, morbidity and mortality in acromegaly based on the Spanish Acromegaly Registry (Registro Espanol de Acromegalia, REA). Eur J Endocrinol 151: 439-446, 2004.

26. Fieffe S, Morange I, Petrossians P, Chanson P, Rohmer V, Cortet C, Borson-Chazot F, Brue T and Delemer B; French Acromegaly Registry: Diabetes in acromegaly, prevalence, risk factors, and evolution: Data from the French Acromegaly Registry. Eur J Endocrinol 164: 877-884, 2011.

27. Bex M, Abs R, T'Sjoen G, Mockel J, Velkeniers B, Muermans K and Maiter D: AcroBel-the Belgian registry on acromegaly: A survey of the 'real-life' outcome in 418 acromegalic subjects. Eur J Endocrinol 157: 399-409, 2007.

28. Arosio M, Reimondo G, Malchiodi E, Berchialla P, Borraccino A, De Marinis L, Pivonello R, Grottoli S, Losa M, Cannavò S, et al: Predictors of morbidity and mortality in acromegaly: An Italian survey. Eur J Endocrinol 167: 189-198, 2012.

29. American Diabetes Association: 4. Comprehensive Medical Evaluation and Assessment of Comorbidities: Standards of Medical Care in Diabetes-2019. Diabetes Care 42 (Suppl 1): S34-S45, 2019.

30. American Diabetes Association: 4. Comprehensive Medical Evaluation and Assessment of Comorbidities: Standards of Medical Care in Diabetes-2020. Diabetes Care 43 (Suppl 1): S37-S47, 2020.

31. Neale G, Hogan H and Sevdalis N: Misdiagnosis: Analysis based on case record review with proposals aimed to improve diagnostic processes. Clin Med (Lond) 11: 317-321, 2011.

32. Singh $\mathrm{H}$ and Graber ML: Improving diagnosis in health care-the next imperative for patient safety. N Engl J Med 373: 2493-2495, 2015.

33. Ball JR and Balogh E: Improving diagnosis in health care: Highlights of a report from the National Academies of Sciences, Engineering, and Medicine. Ann Intern Med 164: 59-61, 2016.

34. Committee on Diagnostic Error in Health Care, Board on Health Care Services, Institute of Medicine, The National Academies of Sciences, Engineering, and Medicine: Improving diagnosis in health care. Balogh EP, Miller BT and Ball JR (eds). National Academies Press (US), Washington, DC, 2015.

35. Mane KK, Rubenstein KB, Nassery N, Sharp AL, Shamim EA, Sangha NS, Hassoon A, Fanai M, Wang Z and Newman-Toker DE: Diagnostic performance dashboards: Tracking diagnostic errors using big data. BMJ Qual Saf 27: 567-570, 2018. 